\title{
First B-HCG predict pregnancy outcome after in-vitro fertilization
}

\section{Sofia Andrade de Oliveira*, Fernanda Silveira Seguro de Carvalho, Julio Elito Júnior}

Department of Gynecology, Federal University of São Paulo, São Paulo, Brazil

Received: 10 January 2017

Revised: 15 January 2017

Accepted: 08 February 2017

\section{*Correspondence:}

Dr. Sofia Andrade de Oliveira,

E-mail: sofia.gineco@gmail.com

Copyright: ( $)$ the author(s), publisher and licensee Medip Academy. This is an open-access article distributed under the terms of the Creative Commons Attribution Non-Commercial License, which permits unrestricted non-commercial use, distribution, and reproduction in any medium, provided the original work is properly cited.

\begin{abstract}
Background: About $22 \%$ of IVF-conceived pregnancies result in spontaneous abortion. Therefore, it is important to predict the complicated and poor pregnancy outcome. Serum human chorionic gonadotrophin levels after 2 weeks of embryo transfer is a reliable marker to predict the pregnancy outcome in patients of IVF. Objective was to correlate the evolution curve of B-HCG after embryo transfer in assisted human reproduction techniques and the pregnancy outcome.

Methods: A prospective and observational study. In patients who underwent embryo transfer, a collection of quantitative B-HCG in $12^{\text {th }}$ day after transfer was made. In patients who had beta-HCG positive value (beta-HCG $>5.0$ $\mathrm{mUI} / \mathrm{ml}$ ), there were two new collections of beta-HCG 48 hours and 72 hours after the first collection. All results have been filed and all pregnancies were accompanied to the final outcome.

Results: It was found that B-HCG values above $139.5 \mathrm{mIU} / \mathrm{ml}$ were associated with a good prognosis gestational. Conclusions: Larger studies are needed to improve these findings and give better information regarding the prognostic value of early pregnancy hCG levels.
\end{abstract}

Keywords: HCG - beta, In vitro fertilization, Pregnancy outcome

\section{INTRODUCTION}

Early pregnancy loss is common during the first trimester, meanly in pregnancies achieved by in vitro fertilization (IVF). ${ }^{1}$ About $22 \%$ of IVF-conceived pregnancies result in spontaneous abortion. ${ }^{2}$ Therefore, it is important to predict the complicated and poor pregnancy outcome. ${ }^{1}$ Although transvaginal ultrasound is a useful tool in assessing early pregnancies, its utility is limited before 5 to 6 weeks of pregnancy. ${ }^{2}$ Early markers with an abnormal rise pattern will allow a clinician to follow a patient more closely and can expedite diagnosis of an ectopic or abnormal intrauterine pregnancy. ${ }^{3}$ Several early-pregnancy serum markers have been evaluated to ascertain outcome, including serum betahuman chorionic gonadotrophin (B-HCG), estrogen, luteinizing hormone $(\mathrm{LH})$ and progesterone. ${ }^{3}$ B-HCG levels after 2 weeks of embryo transfer is a reliable marker to predict the pregnancy outcome in patients of IVF. ${ }^{1}$ Low levels of serum B-HCG in early pregnancy have been reported as a predictor of poor pregnancy outcome such as chemical and ectopic pregnancies as well as spontaneous miscarriage 3 . However, during the IVF treatment, the embryo can be transferred at different developmental stages and it can impact initial B-HCG levels and the majority of studies investigating the prognostic value of B-HCG thresholds did not separate their analyses according to day of ET. ${ }^{4}$

The goals of this study are: describe the evolution curve of B-HCG after embryo transfer in assisted human reproduction techniques and the pregnancy outcome: abortion, ectopic pregnancy, molar trophoblastic pregnancy, twin pregnancy and single pregnancy and, establishing a cutoff point to differentiate an evolutionary pregnancy from a non-evolutionary pregnancy. 


\section{METHODS}

It was a prospective and observational study and it was done in patients who underwent an embryo transfer in the period from $04^{\text {th }}$ February 2014 to $23^{\text {rd }}$ September 2014 in the São Paulo Hospital, São Paulo, Brazil. It was made a collection of quantitative B-HCG in 12th day after the transfer. All collections and laboratory analyzes were made at the central laboratory of the São Paulo Hospital. In patients who had positive value of B-HCG (B-HCG $>5.0 \mathrm{mUI} / \mathrm{ml}$ ), they were performed two new collections of B-HCG 48 hours and 96 hours after the first collection.

They were included, in this study, all patients on IVF Assisted Reproduction treatment who underwent embryo transfer and who agreed to participate of the study through voluntary signature on a consent form explaining all the steps and the study goals.

All results have been filed and all pregnancies were accompanied until the final outcome: abortion, ectopic pregnancy, molar pregnancy, twin pregnancy or single pregnancy.

The monitoring finished after the last birth, in June 2015, of the last embryo transferred in September 2014.

To produce this article, we follow the "strengthening the reporting of observational studies in epidemiology" (STROBE) statement.

\section{Statistical analysis}

After collecting all B-HCG values and after all pregnancy outcomes, it was performed an evolution curve of BHCG titles using the Friedman test. After that, statistic correlations were made between the curve of evolution of beta-HCG and the outcome found. The program used to do the curves was used $\mathrm{R}$ version 3.2.1 software.
In order to find a cut-off of the B-HCG value to discriminate outcome, a ROC curve was performed.

\section{Ethical considerations}

The study was conducted in Human Reproduction Department of the Federal University of São PauloUNIFESP, in Brazil and approved by the Research Ethics Committee of UNIFESP with approval number: CAAE 08835313.0.0000.5505. All participants assigned a consent form explaining all the steps and the study goals.

\section{RESULTS}

Eighty-six patients, in the period from $02^{\text {nd }}$ April 2014 to $23^{\text {rd }}$ September 2014, agreed to participate. After twelve days from the embryo transfer, was performed a blood collection for B-HCG analysis and among the 86 patients, 48 patients had negative results. Among the 38 patients with positive results, five patients did not do the second blood collection and were excluded from the study. Thirty-three patients collected two other blood samples, 48 and 96 hours after the first collection and the results were then analyzed as present below. Table 1 is a summary of the observed frequencies for each outcome during the period of observation after positive B-HCG result. Table 2 is a summary of beta-HCG measures in three days $\left(12^{\text {th }}, 14^{\text {th }}, 16^{\text {th }}\right)$ stratified by outcome.

Table 1: Frequency and percentage observed for the outcome variable.

\begin{tabular}{|lll|}
\hline Outcome & n & $\%$ \\
\hline Negative Beta-HCG & 48 & 59.3 \\
\hline Single pregnancy & 22 & 27.2 \\
\hline Twin pregnancy & 6 & 7.4 \\
\hline Ectopic pregnancy & 2 & 2.5 \\
\hline Abortion & 3 & 3.7 \\
\hline Total & 81 & 100.0 \\
\hline
\end{tabular}

Table 2: Summary quantitative variables stratified by outcome (beta-HCG in $\mathbf{m U I} / \mathbf{m L}$ ).

\begin{tabular}{|c|c|c|c|c|c|c|c|}
\hline Outcome & & $\mathbf{N}$ & Minimum & Mean & Median & Maximum & SD \\
\hline Negative & BHCG 1 & 48 & 0.10 & 0.56 & 0.50 & 3.90 & 0.52 \\
\hline \multirow{3}{*}{$\begin{array}{l}\text { Single } \\
\text { Pregnancy }\end{array}$} & BHCG 1 & 22 & 31.50 & 1459.15 & 979.70 & 9806.00 & 2047.89 \\
\hline & BHCG 2 & 22 & 82.00 & 2729.64 & 1780.00 & 16305.00 & 3434.18 \\
\hline & BHCG 3 & 22 & 142.00 & 5225.55 & 3300.00 & 30416.00 & 6480.41 \\
\hline \multirow[t]{3}{*}{ Twin pregnancy } & BHCG 1 & 6 & 874.70 & 3373.62 & 2402.00 & 9562.00 & 3208.81 \\
\hline & BHCG 2 & 6 & 2600.00 & 6215.17 & 4705.50 & 15000.00 & 4719.07 \\
\hline & BHCG 3 & 6 & 5000.00 & 11689.83 & 9060.00 & 28145.00 & 8811.45 \\
\hline \multirow{3}{*}{$\begin{array}{l}\text { Ectopic } \\
\text { pregnancy }\end{array}$} & BHCG 1 & 2 & 124.70 & 1086.85 & 1086.85 & 2049.00 & 1360.69 \\
\hline & BHCG 2 & 2 & 132.00 & 1199.50 & 1199.50 & 2267.00 & 1509.67 \\
\hline & BHCG 3 & 2 & 90.00 & 1105.50 & 1105.50 & 2121.00 & 1436.13 \\
\hline \multirow[t]{3}{*}{ Abortion } & BHCG 1 & 3 & 20.00 & 43.00 & 51.20 & 57.80 & 20.19 \\
\hline & BHCG 2 & 3 & 1.00 & 35.67 & 3.00 & 103.00 & 58.32 \\
\hline & BHCG 3 & 3 & 0.00 & 43.00 & 2.00 & 127.00 & 72.75 \\
\hline
\end{tabular}


Table 3: Odds ratio of the variable beta HCG (cutoff) considering the variable outcome single or twin) as the response variable.

\begin{tabular}{|lllll|}
\hline Variable & $\begin{array}{c}\text { Odds } \\
\text { ratio }\end{array}$ & \multicolumn{2}{l}{ C.I $95 \%$ for OR } & p \\
\hline $\begin{array}{l}\text { BHCG } \\
\leq 139.5\end{array}$ & - & - & - & - \\
\hline $\begin{array}{l}\text { BHCG } \\
>139.5\end{array}$ & 52.000 & 3.781 & 715.062 & 0.003 \\
\hline
\end{tabular}

We present for each outcome, the average evolution of BHCG along with the confidence interval (95\%) in Figure 1. For single pregnancy outcome, there were significant diferences $(p<0.05)$ in each of the three times, that is, we have evidence of differences between the $12^{\text {th }}$ and $14^{\text {th }}$ days, $12^{\text {th }}$ and $16^{\text {th }}$ days and between $14^{\text {th }}$ and $16^{\text {th }}$ days. However, in twin pregnancy outcome, the difference was in relation to $12^{\text {th }}$ and $16^{\text {th }}$ days. While for the ectopic pregnancy and abortion outcomes no significant difference was found between the three moments. It can see a rise of developments in B-HCG to the outcome single pregnancy and twin pregnancy. On the other hand, for ectopic pregnancy outcomes and abortion average developments are relatively stable behavior. It was not possible to evaluate the percentage change of B-HCG values among the first, second and third collections due to low sample numbers.

Table 4: Results of the first beta-HCG value among evolutionary pregnancy and not evolutionary pregnancy.

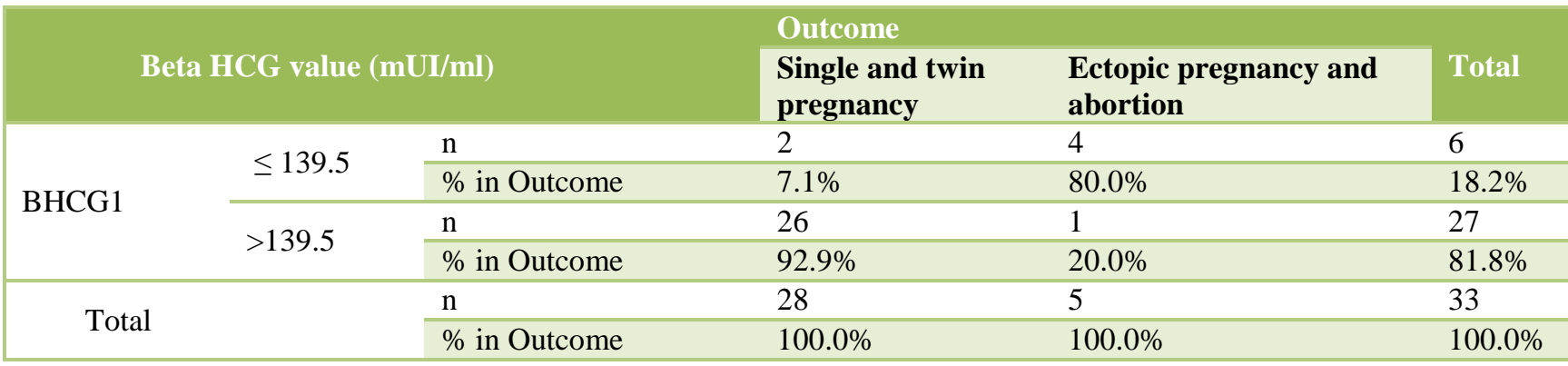

In order to find a cut-off for the first B-HCG value to discriminate outcome, a ROC curve was performed. In the Figure 2 there is the ROC curve, and Table 3 a test summary, containing the area under the curve (accuracy) and the $\mathrm{p}$ value of the argument.

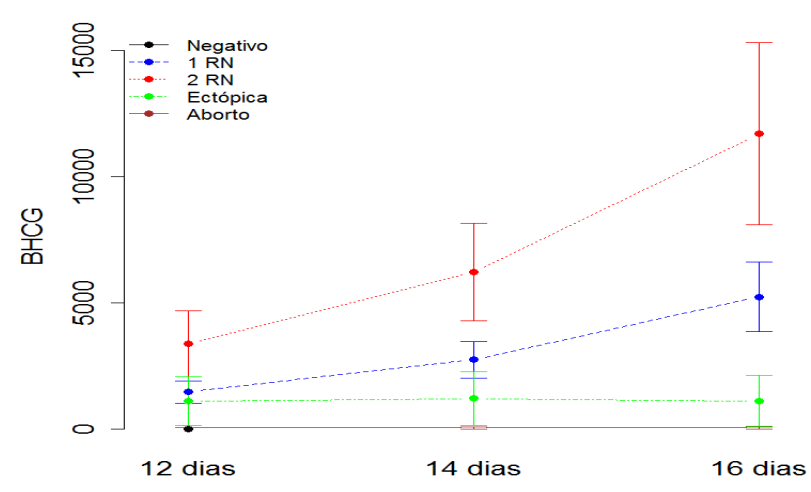

Figure 1: Evolution and average confidence interval 95\% of BHCG for endpoints.

A ROC curve was performed (Figure 2) to choose a cutoff value of B-HCG serum in the $12^{\text {th }}$ that evidence the evolution of a pregnancy to evolutionary pregnancy and not evolutionary pregnancy. The point of the ROC curve that maximizes the sensitivity and specificity simultaneously was the value $139.5 \mathrm{mUI} / \mathrm{ml}$. (Table 3 and Table 4). Considering the value of cut-off, the sensitivity obtained was $92.9 \%$ and specificity was $80 \%$.

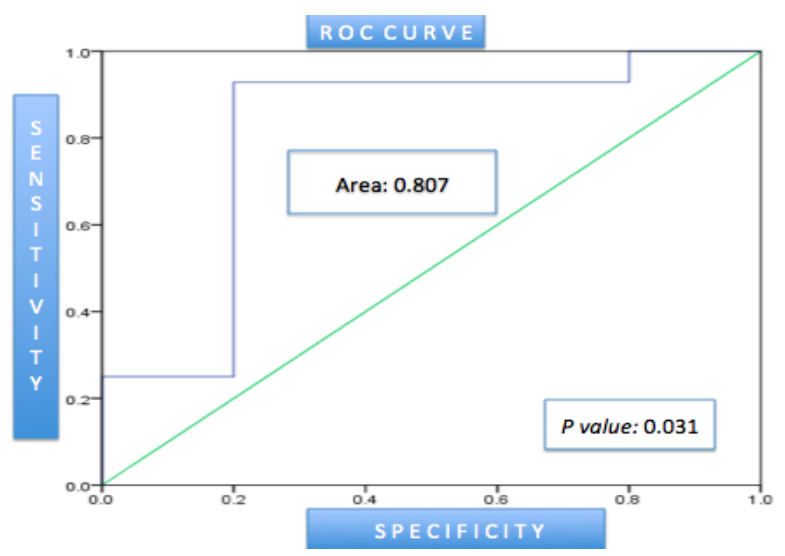

Figure 2: ROC Curve.

Thereby, women who have B-HCG $>139.5 \mathrm{mUI} / \mathrm{ml}$ has 52 times more likely to have the outcome single or twin compared to women who have $\mathrm{B}-\mathrm{HCG} \leq 139.5 \mathrm{mUI} / \mathrm{ml}$.

\section{DISCUSSION}

During cycles of human assisted reproduction treatments, there is a period of great anxiety by the couple that is the 
period between the result of the positive B-HCG and the obstetric ultrasound. ${ }^{3}$ This is an important period because there is still no information about the location of the pregnancy, the number of implanted embryos or about the evolution of that pregnancy. This study aimed to find a B-HCG value that could predict the course of pregnancy and it found that values above $139.5 \mathrm{mIU} / \mathrm{ml}$ were associated with a good pregnancy prognosis. The BHCG represents the functional activity of placental trophoblastic tissue and the low levels are associated with early pregnancy loss or poor outcome. ${ }^{2}$ Present study corroborates with other studies showing that low initial hCG is correlated with no evolutionary pregnancy outcome. $^{5-7}$

\section{CONCLUSION}

Larger studies are needed to improve these findings and give better information regarding the prognostic value of early pregnancy hCG levels and specially information about the percentage change of B-HCG values along the days.

Funding: No funding sources Conflict of interest: None declared

Ethical approval: The study was approved by the Research Ethics Committee of UNIFESP with approval number: CAAE 08835313.0.0000.5505

\section{REFERENCES}

1. Singh N, Goyal M, Malhotra N, Tiwari A, Badiger S. Predictive value of early serum beta-human chorionic gonadotrophin for the successful outcome in women undergoing in vitro fertilization. J Hum Reprod Sci. 2013;6(4):245-7.
2. Lawler CC, Budrys NM, Rodgers AK, Holden A, Brzyski R, Schenken RS. Serum beta human chorionic gonadotropin levels can inform outcome counseling after in vitro fertilization. Fert Sterility. 2011;96(2):505-7.

3. Porat S, Savchev S, Bdolah Y, Hurwitz A, HaimovKochman R. Early serum human chorionic gonadotropin in pregnancies after in vitro fertilization: contribution of treatment variables and prediction of long-term pregnancy outcome. Fert Sterility. 2007;88(1):82-9.

4. Shamonki MI, Frattarelli JL, Bergh PA, Scott RT. Logarithmic curves depicting initial level and rise of serum beta human chorionic gonadotropin and live delivery outcomes with in vitro fertilization: An analysis of 6021 pregnancies. Fert Sterility. 2009;91(5):1760-4.

5. Anupama SQ, Kathiresan A, Cruz-Almeida Y, Barrionuevo MJ, Maxson WS, Hoffman DI, et al. Prognostic value of beta-human chorionic gonadotropin is dependent on day of embryo transfer during in vitro fertilization. Fert Sterility. 2011;96 (6):1362-6.

6. Fong SA, Rodriquez-Ayala H, Louis M, Howland R, McCulloh D, McGovern PG, et al. Early B-HCG levels predict pregnancy outcome. J Soc Gynecol Investig. 2005;12(2):226.

7. Barnhart K, Sammel MD, Chung K, Zhou L, Hummel AC, Guo W. Decline of serum human chorionic gonadotropin and spontaneous complete abortion: defining the normal curve. Obstet Gynecol. 2004;104:975-81.

Cite this article as: de Oliveira SA, de Carvalho FSS, Júnior JE. First B-HCG predict pregnancy outcome after in-vitro fertilization. Int J Reprod Contracept Obstet Gynecol 2017;6:1093-6. 